\title{
ATP-Sensitive Potassium Channels Modulate Glucose Transport in Cultured Human Skeletal Muscle Cells
}

\author{
Taro WASADA, TaKashi YANO*, Masahiko OHTA*, Naoko YUI* and YasuhiKo IWAMOTO \\ Diabetes Center, Tokyo Women's Medical University School of Medicine, Shinjuku-ku, Tokyo 162-8666, Japan \\ ${ }^{*}$ Research Center, Mochida Pharmaceutical Co., Gotenba, Shizuoka 412-0047, Japan
}

\begin{abstract}
Several lines of evidence suggest that ATP-sensitive potassium $\left(\mathrm{K}_{\mathrm{ATP}}\right)$ channels are involved in glucose uptake by insulin target tissues. The aim of the present study was to prove directly the effect of $\mathrm{K}_{\mathrm{ATP}}$ channel activity on glucose transport into cultured human skeletal muscle cells. We used potassium channel openers PCO400 and nicorandil alone or in combination with channel blockers glibenclamide and gliclazide to examine their effects on insulin- or high glucose concentration-induced glucose uptake using 2-deoxy-D- ${ }^{3} \mathrm{H}$-glucose or 3-O-methyl-D- ${ }^{3} \mathrm{H}$ glucose as tracer, respectively. PCO-400 inhibited the basal (non-stimulated) uptake of 2-DG or 3-OMG at the glucose concentration of $5 \mathrm{mM}$. PCO-400 and nicorandil dose-dependently inhibited insulin-stimulated glucose uptake, and their inhibitory effects were reversed by glibenclamide or gliclazide. In addition, PCO-400 inhibited high glucose concentration-facilitated glucose transport in the absence of insulin, and this effect was also antagonized by both sulfonylurea drugs. Regarding the mechanism by which $\mathrm{K}_{\mathrm{ATP}}$ channels modulate glucose transport, we focused on protein kinase $\mathrm{C}$ (PKC), because PKC has been supposed to participate in both insulin- and high glucose concentration-stimulated glucose transport. PMA (phorbol 12-myristate 13-acetate) dose-dependently reversed the PCO-400-induced suppression of insulin-stimulated glucose uptake. On the other hand, PCO-400 at the concentration that inhibited glucose uptake caused no alteration of membrane-associated PKC activity in the presence of insulin or PMA. From these results we conclude that $\mathrm{K}_{\mathrm{ATP}}$ channels modulate the basal and insulin-or high glucose level-stimulated glucose transport in skeletal muscle through a mechanism independent of PKC.
\end{abstract}

Key words: ATP-sensitive potassium channel, $\mathrm{K}_{\mathrm{ATP}}$ channel opener/blocker, Glucose transport, Human skeletal muscle cell, Protein kinase $\mathrm{C}$

(Endocrine Journal 48: 369-375, 2001)

RECENTLY, we reported that the therapeutic use of an ATP-sensitive potassium $\left(\mathrm{K}_{\mathrm{ATP}}\right)$ channel opener nicorandil worsened glycemic control in type 2 diabetic patients with coronary artery disease, due to induction of insulin resistance and not to impairment of insulin secretion [1]. This unexpected observation is intriguing in light of previous reports. In the aerobic rat heart, tolbutamide, a $\mathrm{K}_{\mathrm{ATP}}$ channel inhibitor, markedly stimulated glucose uptake and utiliza-

Received: January 9, 2001

Accepted: April 4, 2001

Correspondence to: Taro Wasada, M.D., Diabetes Center, Tokyo Women's Medical University School of Medicine, Kawada-cho 8-1, Shinjuku-ku, Tokyo 162-8666, Japan tion at clinically relevant dosages $[2,3]$. Pulido et al. [4] demonstrated that diazoxide, a potent $K_{\mathrm{ATP}}$ channel opener, reversed the stimulatory effect of gliclazide on glucose uptake in perfused rat hindquarter muscle preparations. In addition, mice with knocked-out $\mathrm{K}_{\mathrm{ATP}}$ channels in their pancreatic beta cells, skeletal muscle and brain through disrupting the subunit Kir6.2 gene revealed an increased whole-body insulin sensitivity [5]. Taken together, these results support the view that $\mathrm{K}_{\mathrm{ATP}}$ channels, especially those in skeletal muscle, may be involved in glucose transport. However, in vivo or ex vivo studies can not exclude the possibility that the effects of SU drugs or channel openers may be generated by their hemodynamic influence through vascular $\mathrm{K}_{\mathrm{ATP}}$ 
channels rather than their skeletal muscle counterparts.

To date, this issue has not been addressed directly in vitro. In the present study, we therefore investigated how the open or closed state of the $\mathrm{K}_{\mathrm{ATP}}$ channel modulates glucose transport induced by insulin or high glucose concentrations using cultured human skeletal muscle cells, and tried to define the mechanism for $\mathrm{K}_{\mathrm{ATP}}$ channel modulation.

\section{Methods}

\section{A) Materials}

Normal human skeletal muscle cells (SkMC), culture medium containing several growth factors and antibiotics (SkGM), and trypsin/EDTA HEPESbuffered saline for subculture were purchased from Clonetics Co. (San Diego, CA). Fetal bovine serum (FBS) was obtained from Dainippon Pharmaceutical Co. (Tokyo). The solution for the glucose uptake experiment ("uptake solution") was composed of $140 \mathrm{mM} \mathrm{NaCl}, 20 \mathrm{mM}$ HEPES, $5 \mathrm{mM} \mathrm{KCl}, 2.5 \mathrm{mM}$ $\mathrm{MgSO}_{4}, 1 \mathrm{mM} \mathrm{CaCl}_{2}$ in water ( $\mathrm{pH}$ 7.4). The solution for stopping glucose uptake ("stop solution") was made of Dulbecco's PBS (without calcium or magnesium) Tablets (Dainippon Pharmaceutical Co.) containing $10 \mathrm{mM}$ glucose. 2-deoxy-D- ${ }^{3} \mathrm{H}$-glucose (NET-328) was purchased from Dupon-NEN (Boston, MA). 3-O-methyl-D- ${ }^{3} \mathrm{H}$-glucose (TRK-372), $\gamma$ - ${ }^{32} \mathrm{P}-$ ATP (PB10168) and a kit for measuring PKC activity (RPN 77) were purchased from Amersham Pharmacia Biotech (Buckinghamshire, England). PCO400 was obtained from ICN Pharmaceutical (Aurora, $\mathrm{OH})$. Nicorandil was a gift of Chugai Pharmaceutical Co. (Tokyo). The potassium channel openers and blockers were dissolved in dimethyl-sulfoxide (DMSO), the final concentration of which in the uptake solution was $0.1-0.2 \%$. Recombinant human insulin (Novolin R) was provided by Novo-Nordisc Pharma (Copenhagen, Denmark). Unless otherwise stated, all other chemicals were obtained from Wako Pure Chemical Industries (Osaka, Japan).

\section{B) Cell culture}

A subclone of SkMC was cultured in $25 \mathrm{ml}$ of SkGM containing $10 \%$ FBS in $\mathrm{H}_{2} \mathrm{O}$-saturated $5 \%$
$\mathrm{CO}_{2}$ atmosphere at $37^{\circ} \mathrm{C}$ in $75 \mathrm{~cm}^{2}$ tissue culture flasks. After reaching subconfluence, the cells were detached using trypsin/ EDTA containing HEPESbuffered saline, then resuspended in $100 \mathrm{ml}$ SkGM, and were seeded in a volume of $1 \mathrm{ml}$ per well on 12well microplate (for glucose uptake experiments) or of $2 \mathrm{ml}$ per well on 6-well microplate (for PKC activity experiments). After growing to confluence for approximately 4-6 days, the cells were transferred into differentiation medium consisting of SkGM supplemented with $2 \%$ FBS but without growth factors, and allowed to differentiate to myotubes for 610 days. In all of the following experiments, welldifferentiated myotubes were used.

\section{C) Glucose transport}

1) Experiment 1: Insulin-stimulated 2-deoxy-D-glucose (2-DG) uptake

In order to avoid cell damage from high concentrations of the SU drugs, myotubes were incubated with or without glibenclamide $(30-100 \mu \mathrm{M})$ or gliclazide $(300-3000 \mu \mathrm{M})$ in $2 \%$ FBS-containing differentiation medium for a further 18 hours. After washing, the cells were incubated in uptake solution containing 10 or $100 \mu \mathrm{M}$ PCO- 400 or $100-600 \mu \mathrm{M}$ nicorandil and $10 \mu \mathrm{M} 2-\mathrm{DG}$ for $60 \mathrm{~min}$, then $1 \mu \mathrm{M}$ insulin was added, and $20 \mathrm{~min}$ later $25 \mathrm{KBq} / \mathrm{ml}{ }^{3} \mathrm{H}-2-\mathrm{DG}$ was added. Fifteen min later, uptake was rapidly terminated by aspirating off the radioactive incubation medium and washing the cells three times with icecold stop solution. Cells were lysed in $0.4 \mathrm{~N} \mathrm{NaOH}$, and the associated radioactivity was determined by liquid scintillation counting. Nonspecific uptake, which was determined in parallel incubation by inhibiting transporter-mediated uptake with $25 \mu \mathrm{M}$ cytochalasin B, was subtracted from all measurements. 2-DG uptake was calculated by dividing the radioactivity of cell lysate by the ratio of radioactivity of ${ }^{3} \mathrm{H}-2$-DG to the 2-DG concentration in medium.

2) Experiment 2: High glucose concentration-facilitated glucose uptake

Myotubes were incubated with or without glibenclamide $(30-100 \mu \mathrm{M})$ or gliclazide $(300-3000 \mu \mathrm{M})$ as described in Experiment 1. After washing, the cells were transferred into uptake solution containing 10 or $100 \mu \mathrm{M}$ PCO- 400 and 5 or $25 \mathrm{mM}$ glucose, and incubated for $60 \mathrm{~min}$, after which $125 \mathrm{KBq} / \mathrm{ml}^{3} \mathrm{H}-3$ - 
OMG was added. Thirty min later, uptake was rapidly terminated, and cells were washed and lysed. Radioactivity of lysate and nonspecific uptake were measured as described above. Glucose uptake was calculated by dividing the radioactivity of cell lysate by the ratio of radioactivity of ${ }^{3} \mathrm{H}-3-\mathrm{OMG}$ to glucose concentration in the medium.

3) Experiment 3: Effect of PMA on PCO-400-induced suppression of insulin-stimulated 2-DG uptake

As described in Experiment 1, myotubes were washed with uptake solution, and the cells were incubated in the same solution containing $100 \mu \mathrm{M}$ PCO-400 or $0.1 \%$ DMSO for $60 \mathrm{~min}$. Phorbol 12myristate 13-acetate (PMA) at concentrations of 10$100 \mathrm{nM}$ or DMSO (final concentration of $0.2 \%$ ) was added, and after $10 \min 1 \mu \mathrm{M}$ insulin was added and the cells were further incubated for $20 \mathrm{~min}$. Then, ${ }^{3} \mathrm{H}-2-\mathrm{DG}$ was added into the incubation mixture to measure the rate of 2-DG uptake as described in Experiment 1.

4) Experiment 4: Effects of insulin, PCO-400 and PMA on membrane PKC activity

According to the method reported by Cooper et al. [6], myotubes were processed to be gathered, sonicated, and precipitated at $100,000 \times \mathrm{g}$ for $30 \mathrm{~min}$ at $4^{\circ} \mathrm{C}$. Pellets were resuspended in buffer $(50 \mathrm{mM}$ Tris, $\mathrm{pH} 7.5, \quad 0.3 \% \quad \beta$-mercaptoethanol, $10 \mathrm{mM}$ EGTA, $5 \mathrm{mM}$ EDTA, $10 \mathrm{mM}$ benzamidine, $0.28 \mathrm{mM}$ PMSF) and in some experiments they were partially purified by DEAE-Sephacel column chromatography using a step-wise gradient of $0.05-0.15 \mathrm{M} \mathrm{KCl}$. Using these cellular extracts or column eluants, the effects of insulin $(1 \mu \mathrm{M})$, PCO-400 $(100 \mu \mathrm{M})$ and PMA (100 nM) on PKC activity were examined in the same conditions described in Experiment 3. PKC activity was measured by ${ }^{32} \mathrm{P}$-transfer activity after adding $\gamma-{ }^{32} \mathrm{P}$-ATP to the substrate (synthetic peptide) using a commercial kit, and expressed as the activity (pmol of ${ }^{32} \mathrm{P}$ incorporated $/ \mathrm{min}$ ) measured at saturating $\mathrm{Ca}^{2+}$ and phospholipid, minus the "basal" activity measured in the presence of EGTA.

Statistical analysis was performed using ANOVA and Dunnet's test. Data are means \pm SE in triplicate experiments unless otherwise indicated.

\section{Results}

\section{Experiment 1}

PCO-400 exerted an inhibitory effect on the basal 2-DG uptake in the absence of insulin $(90.1 \pm 8.8 \%$ at $10 \mu \mathrm{M}, 82.5 \pm 7.1 \%$ at $100 \mu \mathrm{M}$ PCO $-400, \mathrm{p}<0.05$ vs. basal as 100\%). PCO-400 and nicorandil inhibited insulin-stimulated 2-DG uptake dose-dependently, reaching statistically significant levels at $100 \mu \mathrm{M}$ of PCO-400 (19\% inhibition, p $<0.05$ ) (Fig. 1) and at $600 \mu \mathrm{M}$ of nicorandil (20\% inhibition, $\mathrm{p}<0.01$ ) (Fig. 2). The inhibitory effect of PCO-400 $(100 \mu \mathrm{M})$

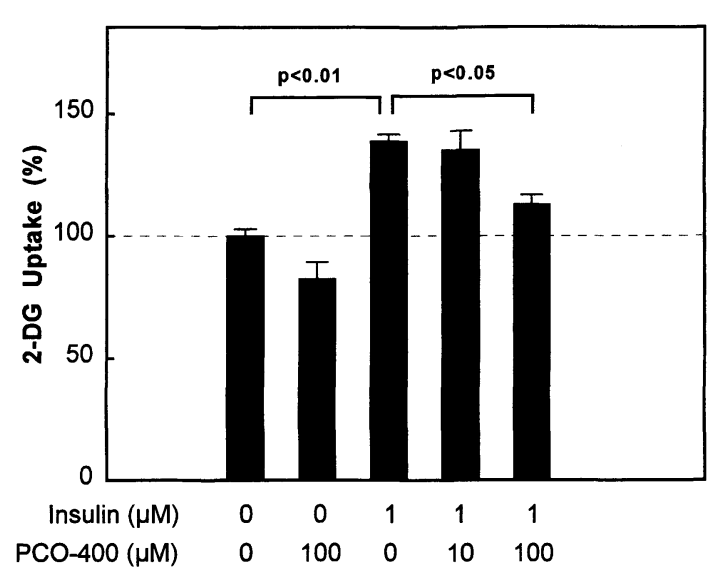

Fig. 1. Effect of PCO-400 (10 or $100 \mu \mathrm{M})$ on basal and insulin $(1 \mu \mathrm{M})$-stimulated 2-DG uptake. Mean $\pm \mathrm{SE}$ $(\mathrm{n}=3)$

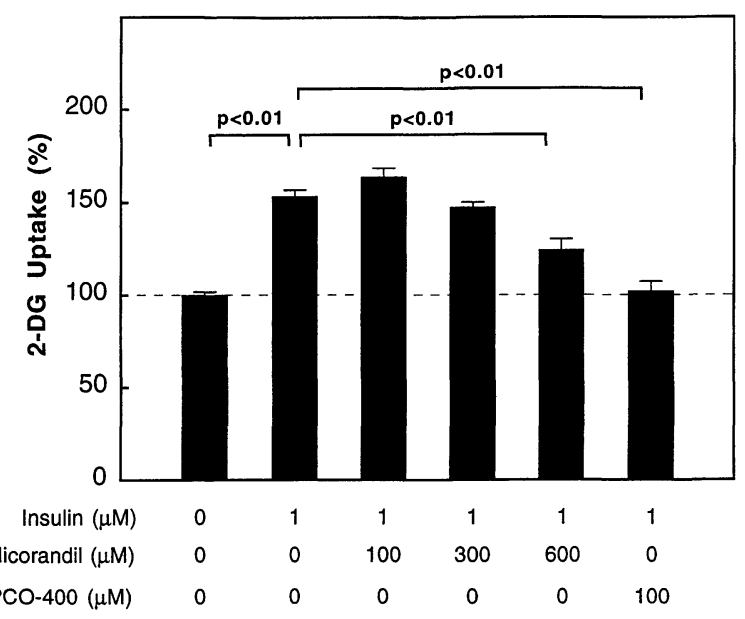

Fig. 2. Effect of increasing concentrations of nicorandil $(100-600 \mu \mathrm{M})$ on insulin $(1 \mu \mathrm{M})$-stimulated 2-DG uptake. Mean $\pm \operatorname{SE}(n=3-4)$ 
was dose-dependently reversed by pretreatment with glibenclamide $(28 \%$ increase at $100 \mu \mathrm{M}, \mathrm{p}<0.01)$ or by gliclazide $(49 \%$ increase at $3000 \mu \mathrm{M}, \mathrm{p}<0.01)$ (Fig. 3).

\section{Experiment 2}

The effect of glucose itself should be examined in the presence of high concentration of glucose. We used ${ }^{3} \mathrm{H}-3-\mathrm{OMG}$ instead of ${ }^{3} \mathrm{H}-2-\mathrm{DG}$, because the uptake of the former is known to be higher than that of the latter under conditions of high glucose concentration as in the present study. PCO-400 showed an inhibition of the basal uptake of glucose at $5 \mathrm{mM}$ $(105 \pm 9 \%$ at $10 \mu \mathrm{M}, 87 \pm 2 \%$ at $100 \mu \mathrm{M}$ PCO -400 , $\mathrm{p}<0.05$ vs. basal as $100 \%$ ). As shown in Fig. 4, uptake of glucose was significantly higher in $25 \mathrm{mM}$ glucose than in $5 \mathrm{mM}$ glucose $(167 \%$ increase, $\mathrm{p}<$ 0.01 ), demonstrating the ability of glucose to facilitate its own transport. PCO-400 dose-dependently suppressed the high glucose concentration-promoted glucose uptake (23\% inhibition at $100 \mu \mathrm{M}$ PCO-400, $p<0.05$ ). The inhibitory effect of PCO- 400 on high

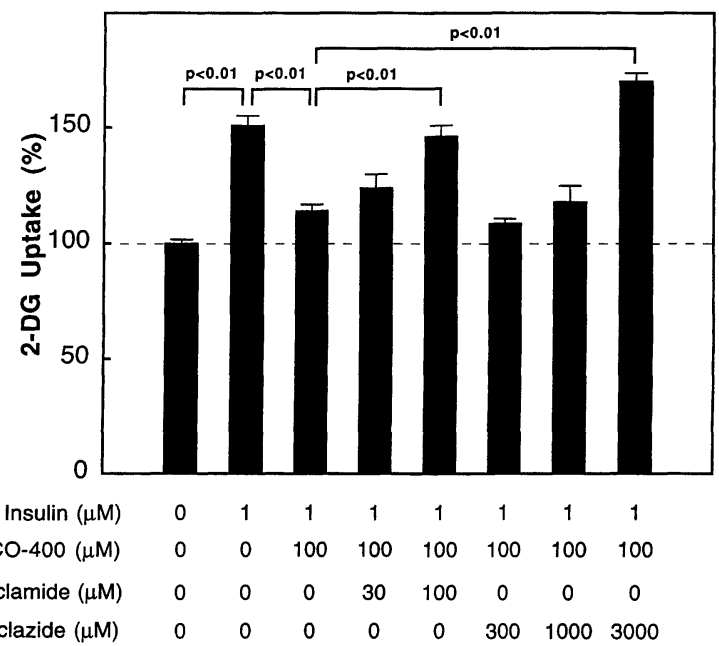

Fig. 3. Effect of glibenclamide $(30-100 \mu \mathrm{M})$ or gliclazide $(300-3000 \mu \mathrm{M})$ on PCO-400-induced inhibition of insulin-stimulated 2-DG uptake. In order to prevent cell damaging by concomitant incubation with high concentrations of glibenclamide or gliclazide and PCO-400 in the protein-free uptake solution, the cells were pretreated with SU drugs for 18 hours in the protein-containing differentiation medium, then subjected to incubation with PCO-400 for $95 \mathrm{~min}$ in the uptake solution, and measuring 2-DG uptake as described in the Methods. Mean $\pm \operatorname{SE}(n=3)$ glucose-induced glucose uptake was reversed by glibenclamide dose-dependently $(38 \%$ increase at $100 \mu \mathrm{M}, \mathrm{p}<0.01)$ and by gliclazide $(27 \%$ increase at $3000 \mu \mathrm{M}, \mathrm{p}<0.01$ ) (Fig. 5).

\section{Experiment 3}

PMA stimulated glucose uptake by $19 \%$ at $10 \mathrm{nM}$ and $31 \%$ at $30 \mathrm{nM}$ PMA in the presence of insulin. 10-100 nM PMA reversed the PCO-400-induced sup-

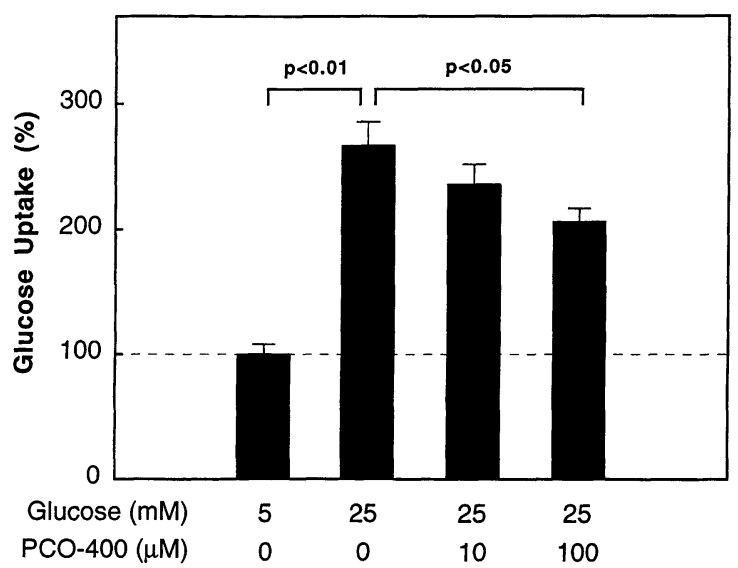

Fig. 4. Effect of PCO-400 (10 or $100 \mu \mathrm{M})$ on high glucose $(25 \mathrm{mM})$-facilitated glucose uptake. Mean \pm SE.

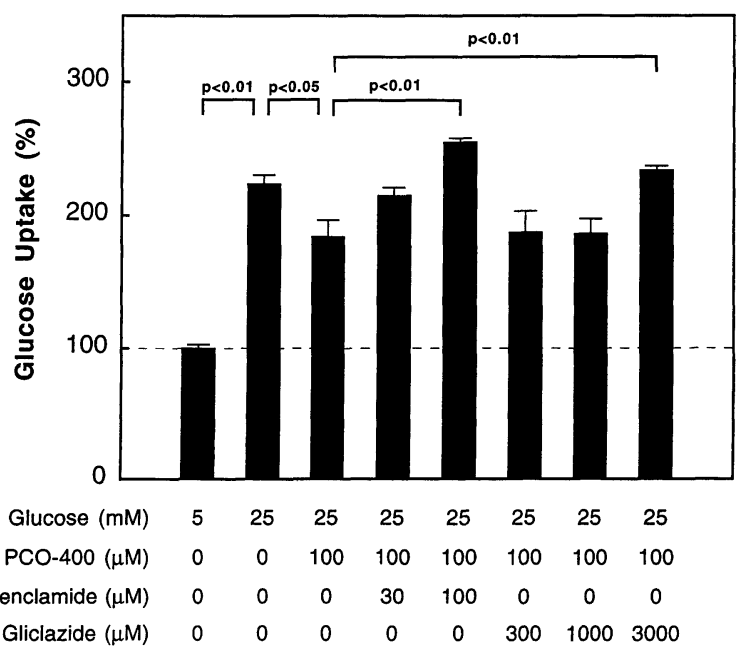

Fig. 5. Effect of glibenclamide $(30-100 \mu \mathrm{M})$ or gliclazide (300-3000 $\mu \mathrm{M})$ on PCO-400-induced inhibition of high glucose $(25 \mathrm{mM})$-facilitated glucose uptake. The cells were first incubated with SU drugs, followed by incubation with PCO-400 for $90 \mathrm{~min}$ as described in the note to Fig. 3. Mean $\pm \operatorname{SE}(n=3)$ 
pression of insulin-stimulated glucose uptake dosedependently and its effect reached a statistically significant level $(21 \%$ increase, $\mathrm{p}<0.01)$ at $100 \mathrm{nM}$ compared with control (Fig. 6).

\section{Experiment 4}

As expected, PMA treatment stimulated $\mathrm{Ca}^{2+}$ - and phospholipid-dependent protein kinase (PKC) of the membrane fraction up to 4-fold above baseline and concomitantly increased insulin-stimulated glucose transport $(119 \%$ at $10 \mathrm{nM}, 131 \%$ at $30 \mathrm{nM}$ of PMA vs. control as $100 \%$ ). However, addition of PCO400 failed to reduce PKC activity in the presence of insulin or PMA (Table 1). We were also unable to

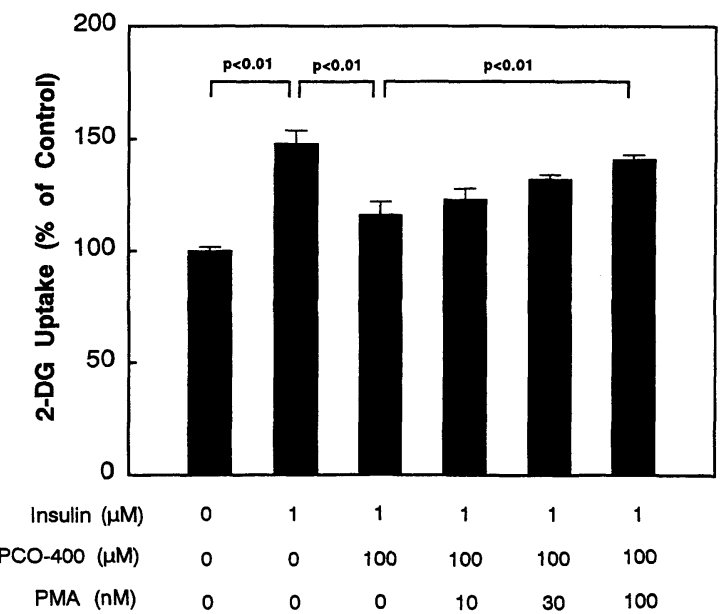

Fig. 6. Effect of PMA (phorbol 12-myristate 13-acetate) on PCO-400-induced inhibition of insulin-stimulated glucose uptake. Cells were successively incubated with $100 \mu \mathrm{M}$ PCO-400 for $50 \mathrm{~min}, 10-100 \mathrm{nM}$ PMA for $10 \mathrm{~min}$, and $1 \mu \mathrm{M}$ insulin for $20 \mathrm{~min}$. 2-DG uptake was measured $15 \mathrm{~min}$ after mixing ${ }^{3} \mathrm{H}-2-\mathrm{DG}$ as described in Methods. Mean $\pm \operatorname{SE}(n=3)$ define the stimulatory effects of insulin on the membrane-associated PKC activity by directly assaying crude extracts as well as eluants following partial purification on DEAE-Sephacel column (Table 1).

\section{Discussion}

In the present study, $\mathrm{K}_{\mathrm{ATP}}$ channel openers PCO400 and nicorandil were shown to inhibit insulinstimulated glucose transport, and their inhibitory effects were reversed by the pretreatment with $\mathrm{K}_{\mathrm{ATP}}$ channel blockers glibenclamide and gliclazide in cultured human skeletal muscle cells. In addition, PCO-400 exerted an inhibitory effect on glucose uptake induced by high concentration of glucose in the absence of insulin. This effect was also antagonized by glibenclamide or gliclazide. These findings directly prove that $\mathrm{K}_{\mathrm{ATP}}$ channels modulate glucose transport in a major insulin-target tissue. The most interesting finding in the present study is that PCO400 inhibited not only insulin-stimulated but also high glucose concentration-facilitated glucose transport, because both glucose transport processes are generally thought to be separate signaling pathways; for example, it has been demonstrated that dantrolene, a potent inhibitor of $\mathrm{Ca}^{2+}$ release from the sarcoplasmic reticulum, blocks the ability of hyperglycemia to increase glucose transport, but has no effect on insulin-stimulated glucose transport [7]. On the other hand, inhibition of phosphatidylinositol (PI) 3-kinase by wortmannin abolished the insulinstimulated glucose transport, but has no effect on the activation of glucose transport by hyperglycemia [7]. Therefore, our observations suggest that a common step may be involved in the action of potassium

Table 1. Measurements of membrane-associated PKC activity

\begin{tabular}{cccccc}
\hline & Control & Ins & Ins + PCO & PMA & PMA+PCO \\
\hline $\mathrm{Ca}^{2+}, \mathrm{PL}+$ & & & & & \\
Crude extract & $100 \pm 5$ & $92 \pm 4$ & $95 \pm 5$ & $443 \pm 13$ & $441 \pm 24$ \\
$\begin{array}{c}\text { DEAE fraction } \\
100 \pm 11\end{array}$ & $85 \pm 21$ & & & \\
$\mathrm{Ca}^{2+}, \mathrm{PL}-$ & & & & & \\
$\quad$ Crude extract & $100 \pm 7$ & $104 \pm 3$ & $100 \pm 4$ & $271 \pm 5$ & $285 \pm 20$ \\
\hline
\end{tabular}

PKC activity/protein was expressed in relative value to control as 100, $n=3-6, \mathrm{PL}$ : phospholipid, Ins: insulin $1 \mu \mathrm{M}$, PCO:PCO-400 $100 \mu \mathrm{M}$, PMA: PMA $100 \mathrm{nM}$, mean $\pm \mathrm{SE}$ 
channel openers. In this regard, we focused on the potential link between $\mathrm{K}_{\mathrm{ATP}}$ channel and PKC in insulin- or high glucose concentration-induced glucose transport, because PKC has been hypothesized to be involved in both processes; that is, insulin activates certain PKC isoforms [8-10] and the insulin effect on glucose transport can be partially suppressed by PKC inhibitors [11, 12]. Similarly, high glucose concentrations lead to activation and translocation to the plasma membrane of both PKC and GLUT4 [12, 13].

In the present study, PMA treatment dose-dependently reversed the PCO-400-induced inhibition of insulin-stimulated 2-DG uptake, plausibly suggesting that PKC exerts an inhibitory effect on $\mathrm{K}_{\mathrm{ATP}}$ channels. This observation is in good agreement with the previous study by Linde et al. [14] who demonstrated that in rat aortic rings phorbol esters inhibit the ${ }^{86} \mathrm{Rb}^{+}$efflux and vasorelaxation evoked by pretreatment with $\mathrm{K}_{\mathrm{ATP}}$ channel opener (P1075). It is also known that $\mathrm{K}_{\mathrm{ATP}}$ channel activity can be modulated by phosphorylation; in general, activation of protein kinase A has been found to be stimulatory, whereas protein kinase $C$ is often inhibitory [15-17]. Thus, our findings that PMA-induced reversal of inhibition by PCO-400 of insulin-stimulated glucose uptake again support $\mathrm{K}_{\mathrm{ATP}}$ channel involvement in this process. PCO- 400 at the concentration that inhibited insulin-induced glucose uptake evoked no change in the membrane-associated PKC activity in the presence of insulin or PMA. This finding seems to contradict the view that PCO-400 acts via PKC. In this regard, it should be pointed out that an atyp-

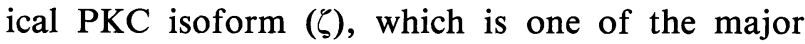
isoforms affected by insulin in skeletal muscle, is not affected by phorbol esters [10]. Therefore, our observed effect of PMA favors the idea that $\mathrm{K}_{\mathrm{ATP}}$ channel openers exert an inhibitory effect via mechanism independent of PKC isoforms implicated in insulin signaling.

Here, some questions in our experiments should be discussed: Firstly, quite a high concentration of insu- lin was required to generate a statistically significant effect on glucose transport. This insensitivity to insulin may depend on a lower level of expression of the insulin receptors or GLUT4 in our cell line, and high concentration of insulin may act through IGF receptors. Although we did not define how abundantly insulin receptors were present and what glucose transporter isoforms were expressed, our finding of 2.5-fold increase in glucose uptake induced by high concentration of glucose in the present cell systems (Fig. 4) seems partly to provide evidence for involvement of GLUT4, because high glucose has been demonstrated to induce a translocation of GLUT4 to the cell surface without insulin [7, 13]. Regarding GLUT1, total membrane levels of this isoform were reported not to be influenced by hyperglycemia $(20 \mathrm{mM})$ in a primary human skeletal muscle culture system [18]. In the present study, nonspecific uptake of glucose by diffusion ("glucose effect") was eliminated by using cytochalasin B. On the other hand, isolated or cultured muscle cells were observed to be less sensitive to insulin or channel selective compounds $[19,20]$. Thus, we believe that $\mathrm{K}_{\mathrm{ATP}}$ channels do modulate the glucose transport by physiological mediator, GLUT4. Secondly, in contrast to the previous studies $[8,9]$, we could not confirm insulin's ability to activate membrane-associated PKC activity in SkMC cells. The reason for this variance may depend on the different cell systems employed. In conclusion, this study does not define the mechanism by which $K_{\text {ATP }}$ channels modulate glucose transport, but provide direct evidence that $\mathrm{K}_{\mathrm{ATP}}$ channel status (open or closed) can influence the basal and stimulated glucose transport by insulin and high concentration of glucose in human skeletal muscle cells.

\section{Acknowledgments}

This work was supported in part by a grant-in-aid from the Ministry of Education, Japan.

\section{References}

1. Wasada $T$, Watanabe $C$, Nakagami $T$, Iwamoto $Y$ (1999) Adenosine triphosphate-sensitive potassium channels are involved in insulin-mediated glucose transport in humans. Metabolism 48: 432-436.

2. Kramer JH, Lampson WG, Schaffer SW (1983) Effect of tolbutamide on myocardial energy metabolism. 
Am J Physiol 245: H313-H319.

3. Tan BH, Wilson GL, Schaffer SW (1983) Effect of tolbutamide on myocardial metabolism and mechanical performance of the diabetic rat. Diabetes 33: 1138-1143.

4. Pulido N, Casla A, Suarez A, Casanova B, Arrieta FJ, Rovira A (1996) Sulphonylurea stimulates glucose uptake in rats through an ATP-sensitive $\mathrm{K}^{+}$ channel dependent mechanism. Diabetologia 39: 2227.

5. Miki $T$, Nagashima $K$, Tashiro $F$, Kotake $K$, Yoshitomi H, Tamamoto A, Gonoi T, Iwanaga T, Miyazaki J, Seino S (1998) Defective insulin secretion and enhanced insulin action in $\mathrm{K}_{\mathrm{ATP}}$ channel-deficient mice. Proc Natl Acad Sci USA 95: 10402-10406.

6. Cooper DR, Konda TS, Standaert ML, Davis JS, Pollet RJ, Farese RV (1987) Insulin increases membrane and cytosolic protein kinase $\mathrm{C}$ activity in BC3H-1 myocytes. J Biol Chem 262: 3633-3639.

7. Nolte LA, Rincon J, Wahlstrom EO, Craig BW, Zierath JR, Wallberg-Henriksson H (1995) Hyperglycemia activates glucose transport in rat skeletal muscle via a $\mathrm{Ca}^{2+}$-independent mechanism. Diabetes 44: $1345-1348$.

8. Farese RV, Standaert ML, Francois AJ, Ways K, Arnold TP, Hernandez H, Cooper DR (1992) Effects of insulin and phorbol esters on subcellular distribution of protein kinase $\mathrm{C}$ isoforms in rat adipocytes. Biochem $J$ 288: 319-323.

9. Ishizuka T, Yamamoto M, Kajita K, Nagashima T, Yasuda K, Miura K, Cooper DR, Farese RV (1992) Insulin stimulates novel protein kinase $\mathrm{C}$ in rat adipocytes. Biochem Biophys Res Commun 183: 814-820.

10. Braiman L, Sheffi-Friedman L, Bak A, Tennenbaum T, Sampson SR (1999) Tyrosine phosphorylation of specific kinase $\mathrm{C}$ isoenzymes participates in insulin stimulation of glucose transport in primary cultures of rat skeletal muscle. Diabetes 48: 1922-1929.

11. Standaert ML, Buckley DJ, Ishizuka T, Hoffman JM, Cooper DR, Pollet RJ, Farese RV (1990) Protein kinase $\mathrm{C}$ inhibitors block insulin and PMA-stimulated hexose transport in isolated rat adipocytes and $\mathrm{BC}^{3} \mathrm{H}$ 1 myocytes. Metabolism 39: 1170-1179.

12. Berti L, Mosthaf L, Kroder G, Kellerer M, Tippmer S, Mushack J, Seffer E, Seedorf K, Haring H (1994) Glucose-induced translocation of protein kinase $\mathrm{C}$ isoforms in rat-1 fibroblasts is paralleled by inhibition of the insulin receptor tyrosine kinase. $\mathrm{J}$ Biol Chem 269: 3381-3386.

13. Galante P, Mosthaf L, Kellerer M, Berti L, Tippmer S, Bossenmaier B, Fujiwara T, Okuno A, Horikoshi H, Haring HU (1995) Acute hyperglycemia provides an insulin-independent inducer for GLUT4 translocation in $\mathrm{C}_{2} \mathrm{C}_{12}$ myotubes and rat skeletal muscle. Diabetes 44: 646-651.

14. Linde C, Loffler C, Quast U (1997) Inhibition by protein kinase $\mathrm{C}$ of ${ }^{86} \mathrm{Rb}^{+}$efflux and vasorelaxation induced by $\mathrm{P} 1075$, a $\mathrm{K}_{\mathrm{ATP}}$ channel opener, in rat isolated aorta. Naunyn-Schmiedeberg's Arch Pharmacol 356: 425-432.

15. Edwards G, Weston AH (1993) The pharmacology of ATP-sensitive $\mathrm{K}^{+}$channels. Ann Rev Pharmacol Toxicol 33: 597-637.

16. Nelson MT, Quayle JM (1995) Physiological roles and properties of potassium channels in arterial smooth muscle. Am J Physiol 268: C799-C822.

17. Quast U (1996) ATP-sensitive $\mathrm{K}^{+}$channels in the kidney. Naunyn-Schmiedeberg's Arch Pharmacol 354: 213-225.

18. Ciaraldi TP, Abrams L, Nikoulina S, Mudaliar S, Henry RR (1995) Glucose transport in cultured human skeletal muscle cells: regulation by insulin and glucose in nondiabetic and non-insulin-dependent diabetes mellitus subjects. J Clin Invest 96: 2820-2827.

19. Barrett-Jolley R, McPherson GA (1998) Characterization of $\mathrm{K}_{\mathrm{ATP}}$ channels in intact mammalian skeletal muscle fibers. Br J Pharmacol 123: 1103-1110.

20. Sarabia V, Ramlal T, Klip A (1990) Glucose uptake in human and animal muscle cells in culture. Biochem Cell Biol 68: 536-542. 